\title{
Impaired left ventricular diastolic filling in patients with familial amyloid polyneuropathy: a pulsed Doppler echocardiographic study
}

\author{
OSAMU KINOSHITA, MINORU HONGO, HIROYOSHI YAMADA, \\ TAKUO MISAWA, JUN KONO, SHINICHI OKUBO, SHU-ICHI IKEDA
}

From the First Department of Internal Medicine and the Third Department of Internal Medicine, Shinshu University School of Medicine, Matsumoto, Japan

SUMMARY To assess left ventricular diastolic filling in patients with amyloid heart disease 1 . patients with familial amyloid polyneuropathy and 15 normal subjects were studied by pulse Doppler echocardiography. None of the patients had clinical evidence of overt heart disease or restrictive cardiomyopathy and only two of them showed ventricular wall thickening. The peato flow velocity of rapid diastolic filling and the acceleration rate of early diastolic inflow were significantly lower in patients with familial amyloid polyneuropathy than in controls. The pressure

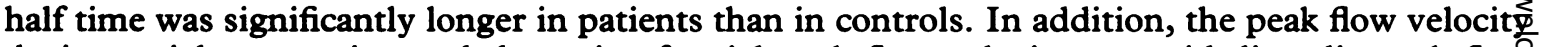
during atrial contraction and the ratio of atrial peak flow velocity to rapid diastolic peak flow velocity were significantly greater in patients than in controls. Although there were no significan correlations between measurements of diastolic filling and clinical findings in patients with familiat amyloid polyneuropathy, the ratio of atrial peak flow velocity to rapid diastolic peak flow velocit was significantly related to left ventricular posterior wall thickness.

These findings suggest that in patients with cardiac amyloidosis without restrictive cardiomyopathy, abnormal left ventricular diastolic filling, manifested by a reduction in the rate and volume of rapid diastolic filling with enhanced atrial contraction, can be seen even in the earl stage of the disease.

Familial amyloid polyneuropathy causes progressive systemic amyloidosis with polyneuropathy that can affect the heart. Amyloid deposits have been reported in the myocardium when there is no clinically identifiable heart disease or ventricular wall thickening. ${ }^{1}$ In earlier serial echocardiographic studies ${ }^{12}$ we found that the development of extensive amyloid deposition caused not only progressive increases in ventricular wall thickness but also altered left ventricular systolic and diastolic function. Left ventricular diastolic filling in several cardiac diseases has been non-invasively assessed by pulsed Doppler echocardiography. But so far the profile of left

Requests for reprints to Dr Minoru Hongo, First Department of Internal Medicine, Shinshu University School of Medicine, 3-1-1 Asahi, Matsumoto 390, Japan.

Accepted for publication 23 August 1988 ventricular diastolic filling in patients with amyloiê heart disease has not been precisely established bo this technique. . $^{3-5}$

We have assessed left ventricular diastolic filling in patients with familial amyloid polyneuropathy who had no clinical evidence of overt heart disease.

\section{Patients and methods}

PATIENTS

We studied 12 patients with familial amyloid poly neuropathy (seven men and five women, aged 28 59 years; mean (SD) 42 (9)) and 15 healthy controis ( 10 men and five women, aged 27 to 58 years; mea⿳亠 (SD) 40 (10)). All patients were referred to us fror several locations in Nagano Prefecture in the centro part of Japan ${ }^{6}$ and the diagnosis was based of neurological findings and amyloid deposits in biops 
specimens of the stomach, rectum, or sural nerve. None had clinically overt heart disease or restrictive cardiomyopathy or any known concomitant heart disease. The duration of illness ranged from 1.5 to 11 years (mean (SD) $6 \cdot 2$ (3.0)). Biopsy specimens of the right ventricular endomyocardium were taken from eight of the 12 patients and all of them showed histological evidence of amyloid deposition. Each subject gave informed consent at the time of the study.

\section{MODE AND PULSED DOPPLER ECHO-}

CARDIOGRAPHIC EXAMINATIONS

Cross sectionally guided $M$ mode and pulsed Doppler echocardiograms were obtained with a commercially available cross sectional Doppler echocardiograph (Toshiba, model SSH-40A/SDS-21A), with a $2.4 \mathrm{MHz}$ transducer, at paper speeds of 50 to $100 \mathrm{~mm} / \mathrm{s}$. All subjects were examined in the left lateral recumbent position and were in sinus rhythm with heart rate of 62 to 74 beats $/ \mathrm{min}$ at the time of the study.

In the $M$ mode echocardiographic examination, the following variables were measured according to the criteria recommended by the American Society of Echocardiography ${ }^{7}$ : (a) left ventricular end diastolic and end systolic dimension and $(b)$ left ventricular posterior wall thickness at end diastole. All measurements were made in at least three cardiac cycles and averaged with the aid of a computer interfaced graphic analyser (Kontron, model Cardio200). Then fractional shortening was calculated.

Doppler recordings of transmitral flow velocity were taken through an apical four chamber view with the Doppler cursor oriented parallel to the long axis plane of the left ventricle and the sample volume carefully placed at the level of the mitral annulus (fig 1). The following measurements were obtained (fig 2): (a) peak flow velocity of left ventricular rapid diastolic filling (peak $E$ ), (b) peak flow velocity during atrial contraction (peak $A),(c)$ the ratio of peak $A$ to peak $E,(d)$ acceleration rate of left ventricular early diastolic flow, $(e)$ acceleration time of early diastolic flow, and $(f)$ pressure half time, which is defined as the time from peak $E$ to peak $E / \sqrt{ } 2 .^{8}$

\section{STATISTICAL ANALYSIS}

Data are expressed as mean (SD) and were analysed by an unpaired $t$ test. Correlations between measurements derived from Doppler echocardiography and clinical and $M$ mode echocardiographic findings were assessed by linear regression analysis. Statistical significance was assumed when the $p$ value was $<0.05$.

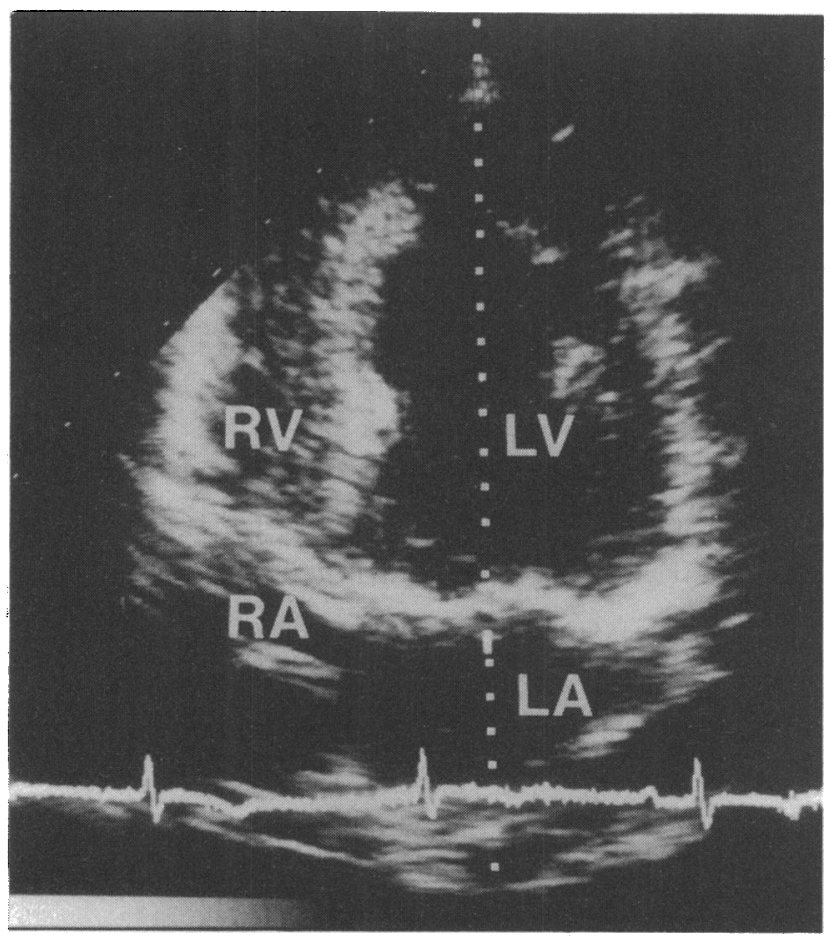

Fig 1 Stop frame cross sectional echocardiogram in the apical four chamber view showing the typical position of the pulsed Doppler sample volume used to obtain left ventricular diastolic flow-velocity waveforms. The sample volume is positioned just below the mitral valve annulus. $L A$, left atrium; $L V$, left ventricle; $R A$, right atrium; $R V$, right ventricle. 


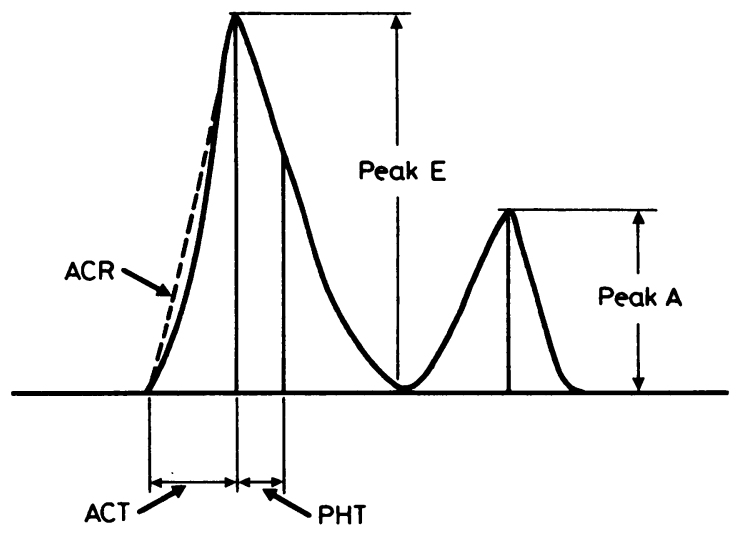

Fig 2 Measurement of the left ventricular inflow pattern. $A C R$, acceleration rate of left ventricular early diastolic flow; $A C T$, acceleration time of left ventricular early diastolic flow; $P H T$, pressure half time; peak $A$, peak flow velocity during atrial contraction; peak $E$, peak flow velocity of left ventricular rapid diastolic filling.

\section{Results}

\section{MODE ECHOCARDIOGRAPHIC FINDINGS}

Table 1 shows that the age and sex distribution, heart rate, left ventricular cavity size, and fractional shortening were similar in patients with familial amyloid polyneuropathy and in controls. Although $10(83 \%)$ of the 12 patients had normal left ventricular posterior wall thickness, this was slightly but significantly greater in patients than in controls.

\section{PULSED DOPPLER ECHOCARDIOGRAPHIC FINDINGS}

The peak $E$ during rapid diastolic filling and the acceleration rate of early diastolic flow in patients with familial amyloid polyneuropathy were 39 (9) $\mathrm{cm} / \mathrm{s}$ and $352(73) \mathrm{cm} / \mathrm{s}^{2}$, compared with $51(11) \mathrm{cm} / \mathrm{s}$ $(\mathrm{p}<0.01)$ and $514(130) \mathrm{cm} / \mathrm{s}^{2}(\mathrm{p}<0.001)$ in controls, respectively. The pressure half time was

Table 1 Clinical characteristics of patients with familial amyloid polyneuropathy (FAP)

\begin{tabular}{|c|c|c|c|}
\hline & $F A P$ & Controls & p value \\
\hline $\begin{array}{l}\text { Number } \\
\text { Age (mean (SD)) } \\
\text { Male/female } \\
\text { Duration of illness (yr) } \\
\text { HR (beats/min) } \\
\text { EDD (mm) } \\
\text { ESD (mm) } \\
\text { PWT (mm) } \\
\% \text { FS }(\%)\end{array}$ & $\begin{array}{l}12 \\
42(9) \\
7 / 5 \\
6 \cdot 2(3 \cdot 0) \\
64(4) \\
46(4) \\
31(6) \\
9 \cdot 6(2 \cdot 9) \\
36(5)\end{array}$ & $\begin{array}{l}15 \\
40(10) \\
10 / 5 \\
66(4) \\
48(4) \\
32(4) \\
8 \cdot 3(0 \cdot 6) \\
38(4)\end{array}$ & $\begin{array}{l}\text { NS } \\
\text { NS } \\
\text { NS } \\
\text { NS } \\
<0.05 \\
\text { NS }\end{array}$ \\
\hline
\end{tabular}

EDD, end diastolic diameter; ESD, end systolic diameter; \%FS, percentage fractional shortening; HR, heart rate; PWT, left ventricular posterior wall thickness.

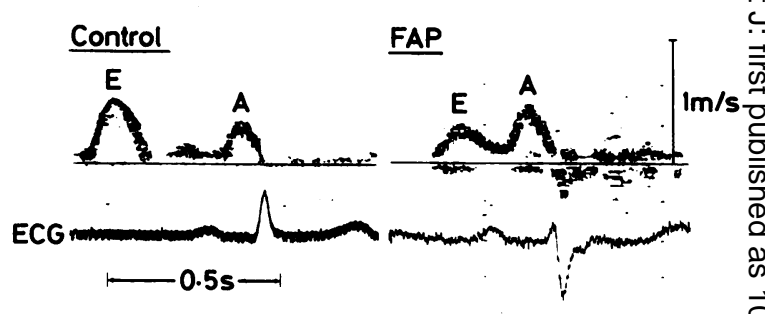

Fig 3 Pulsed Doppler waveform of left ventricular diastolic flow velocity. Left panel, from a 41 year old control with peak flow velocity of left ventricular rapid diastolic filling (E) higher than peak flow velocity during atrial contraction (A). Right panel, from a 38 year old patient with familial amyloid polyneuropathy $(F A P)$ with $A$ higher than $E$. ECG, electrocardiogram.

significantly longer in patients than in controls $(70$ (8) $v 52(10) \mathrm{ms}, \mathrm{p}<0.001)$. The peak A during atrial contraction and the ratio of peak $A$ to peak $E$ were significantly greater in patients than in controls $\left(422^{2}\right.$ (6) $v 30(7) \mathrm{cm} / \mathrm{s}, \mathrm{p}<0.001$ and $1.14(0.28) v 0.62 \mathrm{v}$ $(0 \cdot 19), \mathrm{p}<0.001$, respectively) (fig 3 and table 2 ). OR the 10 patients without ventricular wall thickening $\overrightarrow{0}$ nine showed abnormal left ventricular diastolico filling. These included reduced peak $E$ in sever patients, decrease in the acceleration rate of earlye diastolic flow in five, prolonged pressure half time in nine, enhanced peak $A$ in seven, and increased ration of peak $A$ to peak $E$ in eight.

Although there were no significant correlations between measurements of left ventricular diastoliê filling and heart rate, left ventricular cavity size, or fractional shortening, the ratio of peak $A$ to peak was significantly related to left ventricular posterior wall thickness $(r=-0.66, p<0.05)$. In addition, noD measurement correlated significantly with age and duration of illness, though the frequency and magnitude of abnormalities in peak $E$, peak $A$, and the ratio. of peak $A$ to peak $E$ tended to increase with age and duration of illness (figs 4 and 5).

\section{Discussion}

Our results show that in patients with familiak amyloid polyneuropathy an abnormal pattern of left ventricular diastolic filling is detected by transmitras

Table 2 Mean (SD) Doppler flow measurements

\begin{tabular}{|c|c|c|c|}
\hline Measurement & $F A P$ & Controls & p value \\
\hline $\begin{array}{l}\text { Peak E (cm/s) } \\
\text { Peak A (cm/s) } \\
\text { Peak A/Peak E } \\
\left.\text { ACR (cm/s }{ }^{2}\right) \\
\text { ACT (ms) } \\
\text { PHT (ms) }\end{array}$ & $\begin{array}{l}39(9) \\
42(6) \\
1 \cdot 14(0 \cdot 28) \\
352(73) \\
108(19) \\
70(8)\end{array}$ & $\begin{array}{c}51(11) \\
30(7) \\
0.62(0 \cdot 19) \\
514(130) \\
104(25) \\
52(10)\end{array}$ & $\begin{array}{l}<0.01 \\
<0.001 \\
<0.001 \\
<0.001 \\
\text { NS } \\
<0.001\end{array}$ \\
\hline
\end{tabular}



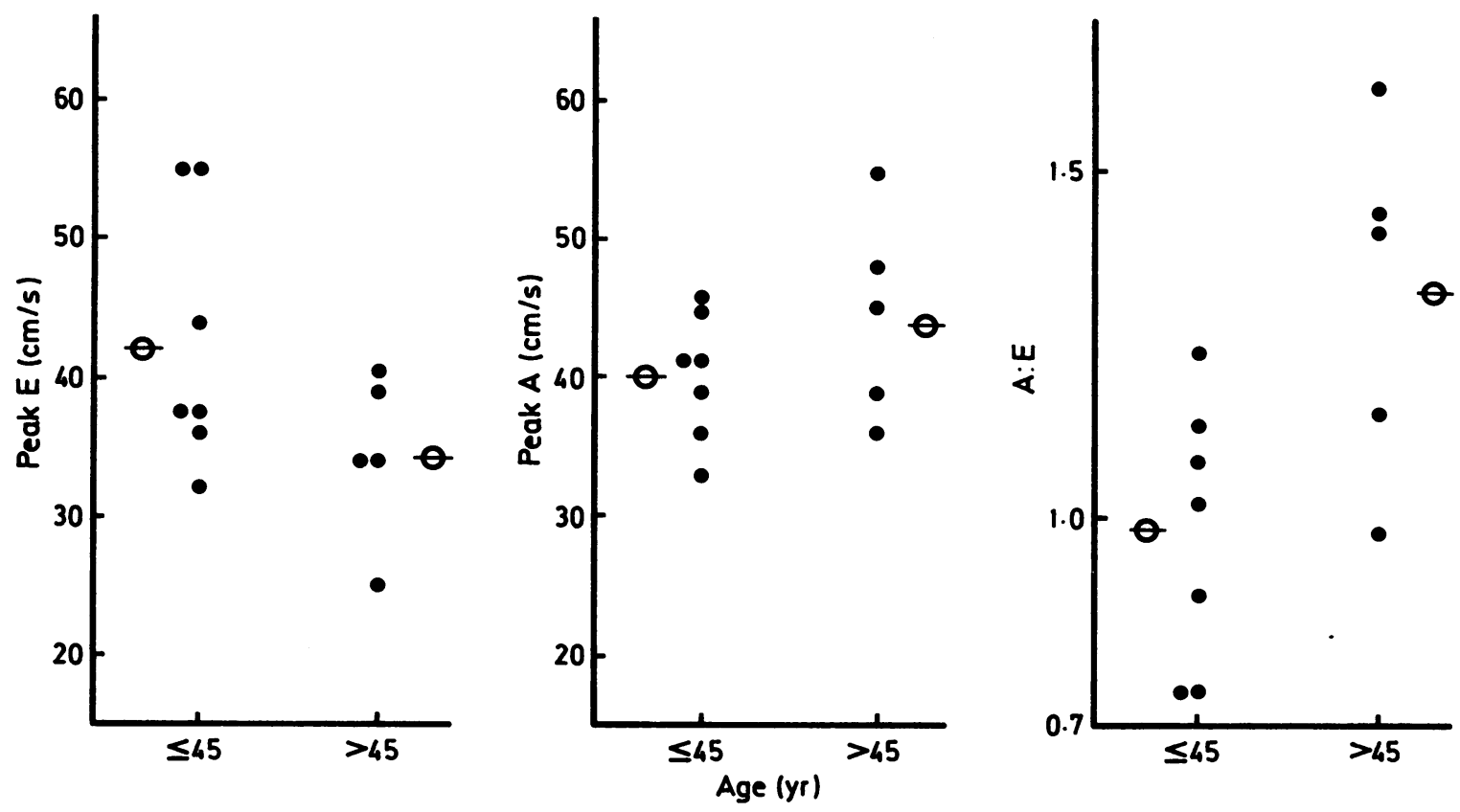

Fig 4 Comparison of measurements of left ventricular filling between patients with familial amyloid polyneuropathy aged $\leqslant$ 45 and $>45$ (peak flow velocity of left ventricular rapid diastolic filling (peak $E$ ), peak flow velocity during atrial contraction (peak $A$ ), and the ratio of peak $A$ to peak $E(A: E))$. Mean values are also given.
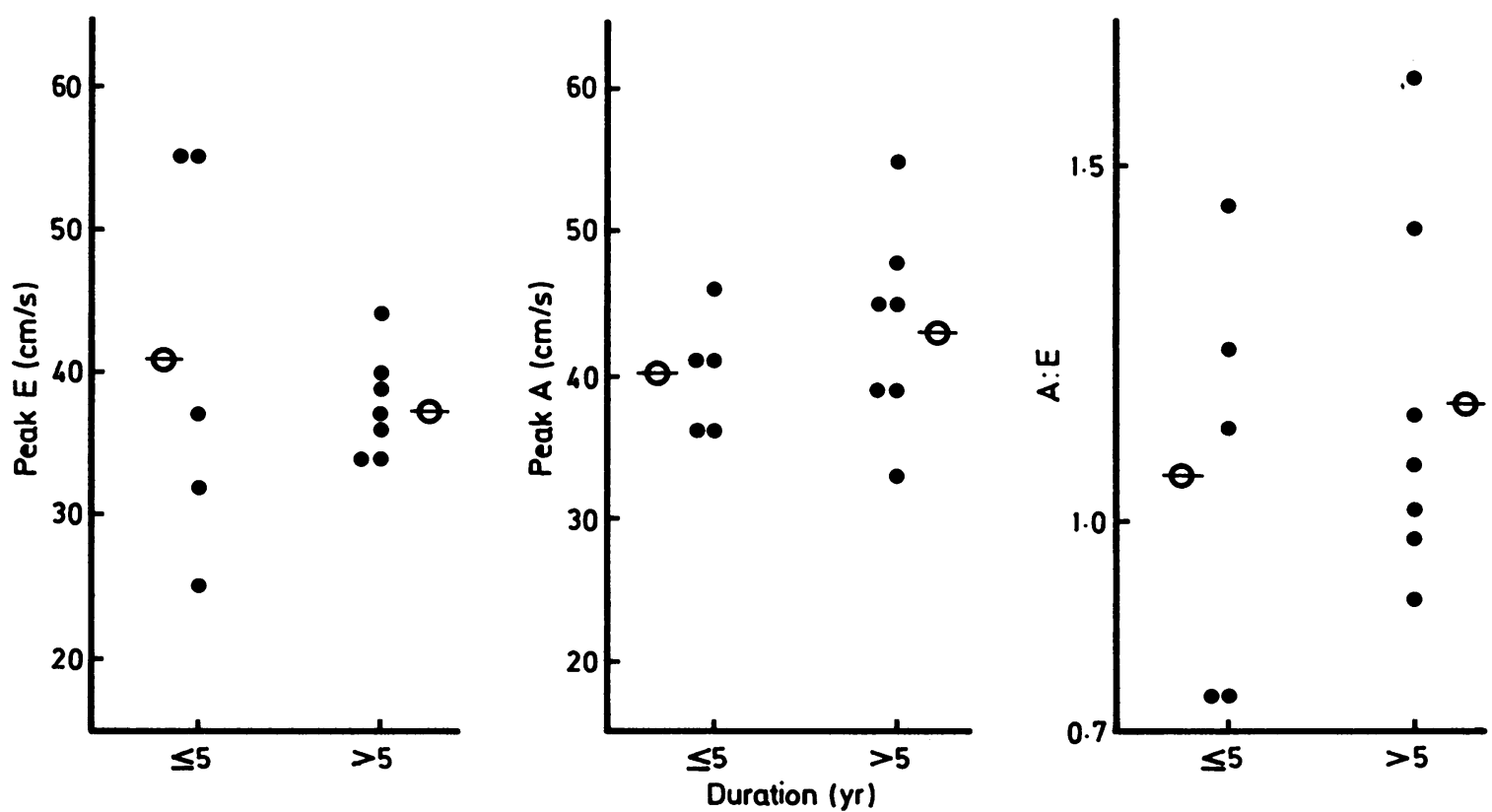

Fig 5 Comparison of measurements of left ventricular filling between patients with familial amyloid polyneuropathy who had been ill for less than five years and those ill for more than five years (peak $E$ measurements, peak $A$ measurements, and ratio of peak $A$ to peak $E(A: E)$ measurements). Mean values are also given. 
flow velocity and that this can be identified even in the absence of clinically overt heart disease, ventricular wall thickening, and abnormal systolic function. Our results also show that abnormalities in diastolic filling increase with age and the duration of illness in patients with familial amyloid polyneuropathy.

\section{LEFT VENTRICULAR DIASTOLIC FILLING IN} PATIENTS WITH AMYLOID HEART DISEASE

Numerous invasive and non-invasive studies have shown that left ventricular diastolic filling is invariably impaired in patients with amyloid heart disease. Catheter studies showed an accelerated rapid diastolic filling followed by a cessation of filling in mid to late diastole in patients with amyloid restrictive cardiomyopathy. ${ }^{910}$ But uniformly depressed filling was reported in some patients in the absence of a dip and plateau pattern in left ventricular pressure recordings. ${ }^{10}{ }^{11}$ Recently St John Sutton et al used digitised $\mathbf{M}$ mode echocardiography to show a prolonged isovolumic relaxation time and reduced peak filling rate of rapid diastolic filling in patients with primary and myeloma associated amyloidosis. ${ }^{12}$ More recently, a range of abnormalities in left ventricular diastolic filling has been reported in patients with amyloid heart disease studied by pulsed Doppler echocardiography. In patients without obvious echocardiographic evidence of myocardial involvement, impaired relaxation of the left ventricle was manifested by a decrease in the rate and volume, as well as a prolongation of rapid filling and enhanced atrial systolic filling. ${ }^{5}$ On the other hand, in patients with increased chamber stiffness with resultant restriction of diastolic filling, rapid filling rate was increased and was accompanied by normal or reduced atrial systolic filling of the left ventricle. ${ }^{35}$ Thus both types of abnormal diastolic filling seem to be present to variable degrees in patients with amyloid heart disease.

In our study an abnormal pattern of left ventricular diastolic filling was detected in many patients with familial amyloid polyneuropathy and was characterised by a reduction in the rate and volume as well as a prolongation of rapid diastolic filling with exaggerated atrial systolic filling. In most of our patients amyloid heart disease was in the early stages $^{12}$ : none of them showed clinically overt heart disease, restrictive cardiomyopathy, or abnormal fractional shortening and most had normal ventricular wall thickness. Our Doppler findings were consistent with those of Plehn et al ${ }^{4}$ and Klein et al, ${ }^{5}$ in which patients had no evidence or slight echocardiographic evidence of myocardial involvement. Our results also confirmed that abnormal left ventricular diastolic filling can be seen before the development of clinically overt heart disease, left $c$. ventricular wall hypertrophy, or abnormal systolic $\underset{\vec{F}}{\vec{F}}$ function. ${ }^{13}$

In our study only the ratio of peak $A$ to peak $E$ ? correlated significantly with the thickness of the left $\frac{\bar{c}}{\mathrm{~N}}$. ventricular posterior wall, while individual peak $\vec{\nabla}$ velocities or other clinical findings did not. Although $\propto$ the flow direction at the centre of the mitral orifice is might be assumed to be perpendicular to the mitral $\vec{\circ}$ annulus, it was difficult to be certain that the apical view showed the true alignment of the mitral $\omega_{\sigma}$ annulus. This might explain why only the ratio of peak A to peak E, which eliminated this factor, correlated with the wall thickness. In patients with $\rightarrow$ amyloid heart disease, ventricular wall hypertrophy? has generally been reported to be caused by amyloid $\stackrel{\oplus}{\oplus}$ infiltration into the myocardium as well as resultanto fibrosis. ${ }^{14} 15$ We did not measure the extent of amyloid ${ }_{-}^{3}$ infiltration or fibrosis in any of our patients.

We believe that the mechanism for abnormal $\frac{\mathbb{D}}{O}$ diastolic filling in this disorder is likely to be abnormal left ventricular distensibility related to interstitial accumulation of amyloid and collagen. $\vec{\varphi}$ Furthermore, myocardial ischaemia may also lead to $\infty_{0}^{\circ}$ abnormalities in diastolic filling; several necropsy studies showed amyloid deposits in the intramuralo coronary arteries in patients with cardiac amyloidosis. ${ }^{14} 16-18$

\section{CLINICAL IMPLICATIONS}

We found age related changes in peak $E$, peak $A$, and $\vec{O}$ the ratio of peak $A$ to peak $E$ in patients with familial ${ }^{3}$ amyloid polyneuropathy. Moreover, abnormalities in these measurements increased with the duration of illness. So these factors must be considered when $\vec{\sigma}_{\bar{\phi}}$ assessing diastolic events in patients with familial amyloid polyneuropathy.

We thank Dr Shozo Kusama, Professor of the First $\delta$ Department of Internal Medicine, Shinshu University School of Medicine, for his critical review of this paper.

This study was supported in part by grants from the Ministry of Health and Welfare Primary Amyloidosis Research Committee, Japan.

\section{References}

1 Hongo M, Ikeda SI. Echocardiographic assessment of the evolution of amyloid heart disease: a study with familial amyloid polyneuropathy. Circulation 1986; 73:249-56.

2 Hongo M, Hirayama J, Fujii T, et al. Early identification of amyloid heart disease by technetium-99mpyrophosphate scintigraphy: a study with familial amyloid polyneuropathy. Am Heart J 1987;113: 654-62. 
3 Plehn JF, Skinner M, Cohen AS, Apstein CS. Atrial failure in cardiac amyloidosis [Abstract]. J Am Coll Cardiol 1986;7:97A.

4 Plehn JF, Dilsizian V, Skinner M, Cohen AS. Ventricular diastolic abnormalities in primary amyloidosis without obvious cardiac involvement [Abstract]. Circulation 1986;74(suppl II):II-451.

5 Klein AL, Luscher TF, Hatle LV, et al. Spectrum of diastolic function abnormalities in cardiac amyloidosis [Abstract]. Circulation 1987;76(suppl IV):IV-126.

6 Ikeda SI, Hanyu N, Hongo M, et al. Hereditary generalized amyloidosis with polyneuropathy: clinicopathological study of 65 Japanese patients. Brain 1987;110:315-37.

7 Sahn DJ, DeMaria A, Kisslo J, Weyman A. Recommendations regarding quantitation in $\mathrm{M}$-mode echocardiographic measurements. Circulation 1978; 58:1072-83.

8 Thomas JD, Weyman AE. Doppler mitral pressure half time: a clinical tool in search of theoretical justification. J Am Coll Cardiol 1987;10:923-9.

9 Meaney E, Shabetai R, Bhargava V, et al. Cardiac amyloidosis, constrictive pericarditis and restrictive cardiomyopathy. Am J Cardiol 1976;38:547-56.

10 Swanton RH, Brooksby IAB, Davies MJ, Coltart DJ, Jenkins BS, Webb-Peploe MM. Systolic and diastolic ventricular function in cardiac amyloidosis. $A m J$
Cardiol 1977;39:658-64.

11 Chew C, Ziady GM, Raphael MJ, Oakley CM. The functional defect in amyloid heart disease. $A m \mathrm{~J}$ Cardiol 1975;36:438-44.

12 St John Sutton MG, Reichek N, Kastor JA, Guiliani ER. Computerized M-mode echocardiographic analysis of left ventricular dysfunction in cardiac amyloid. Circulation 1982;66:790-9.

13 Borer JS, Henry WL, Epstein SE. Echocardiographic observation in patients with systemic infiltrative disease involving the heart. Am J Cardiol 1977;39: 184-8.

14 Buja LM, Khoi NB, Roberts WC. Clinically significant cardiac amyloidosis: clinicopathologic findings in 15 patients. Am J Cardiol 1970;26:394-405.

15 Bhandari AK, Nanda NC. Myocardial texture characterization by two-dimensional echocardiography. $\mathrm{Am}$ $J$ Cardiol 1983;51:817-25.

16 Smith RL, Hutchins GM. Ischemic heart disease secondary to amyloidosis of intramyocardial arteries. Am J Cardiol 1979;44:413-7.

17 Suffitz JE, Sazama K, Roberts WC. Amyloidosis limited to small arteries causing angina pectoris and sudden death. Am J Cardiol 1983;51:1234-5.

18 Cueto-Garcia L, Tajik AJ, Kyle RA, Edwards WD, Wood DL, Seward JB. Echocardiographic features of amyloid ischemic heart disease. Am J Cardiol 1985; 55:606-7. 